\title{
A SOCIOSSEXUALIDADE COMO FERRAMENTA PARA A AUTONOMIA SEXUAL'
}

\author{
Laura Maria Stoppa ${ }^{2}$ \\ SOCIOSEXUALITY AS A TOOL FOR SEXUAL AUTONOMY \\ LA SOCIO SEXUALIDAD COMO HERRAMIENTA PARA LA AUTONOMÍA SEXUAL
}

Resumo: O presente artigo busca esclarecer o conceito da sociossexualidade e sua relevância para o entendimento dos comportamentos sexuais desprovidos ou não de compromisso social e conexão emocional. Para tanto, foram analisados estudos sobre o tema, assim como seus achados sobre os possíveis impactos do sexo casual na vida de seus praticantes tendo como norteadora a orientação sociossexual e os comportamentos "autônomos" ou "não autônomos". Também é verificada a importância da autonomia sexual para a construção e manutenção de uma sexualidade saudável.

Palavras-chave: Sociossexualidade. Sexo casual. Sexualidade. Autonomia. Práticas sociais.

\begin{abstract}
This paper aims to clarify the sociosexuality concept and its relevance for the understanding of non-committed sexual behaviors and emotional connection. Studies were analyzed about the subject as well as their findings about the possible impacts of casual sex on the life of its adepts having sociosexual orientation as a guide for it. This allowed a greater understanding of the "autonomous" and "non-autonomous" behaviors. It was also verified the importance of sexual autonomy to the construction and maintenance of a healthy sexuality.
\end{abstract}

Keywords: Sociosexuality. Casual sex. Sexuality. Autonomy. Social behavior.

Resumen: El presente artículo busca esclarecer el concepto de la socio sexualidad y su relevancia para el entendimiento de los comportamientos sexuales que tienen o no compromiso social y conexión emocional. Por lo tanto se analizaron estudios sobre el tema, así como sus conclusiones sobre los posibles impactos del sexo casual en la vida de sus practicantes teniendo como base la orientación socio sexual y los comportamientos "autónomos” o "no autónomos”. Ainda se comprueba la importancia de la autonomía sexual para la construcción y mantenimiento de una sexualidad sana.

Palabras clave: Socio sexualidade. Sexo casual. Sexualidad. Autonomía. Prácticas sociales.

\section{O conceito sociossexualidade e sua relevância para escolhas sexuais satisfatórias}

A atividade sexual pode frequentemente ser fonte de desconforto, sentimento de inadequação, dor física e/ou psicológica, frustração, constrangimento e, essencialmente, questionamentos. Tais sensações estão intimamente relacionadas às condições em que a atividade ocorre e à condição geral dos indivíduos envolvidos. À tendência comportamental global de engajar ou não em relações sexuais desprovidas de compromisso emocional e/ou social é dado o nome de sociossexualidade.

O conceito, que também pode ser denominado orientação sociossexual, foi inserido pelo biólogo norte-americano Alfred Kinsey (1894-1956) em seus trabalhos "Comportamento sexual no macho humano" e "Comportamento sexual na fêmea humana" (KINSEY et al., 1948, 1953) com uma abordagem adequada à sua formação, aos conhecimentos disponíveis e à maneira de tratar da sexualidade humana na época - da forma mais

\footnotetext{
I Artigo baseado na monografia Sexo casual: desafios educativos, apresentada como conclusão de curso de Pós-Graduação em Educação em Sexualidade do Centro Universitário Salesiano (UNISAL), 2018, sob orientação da Prof ${ }^{a}$ Ana Canosa.

2 Jornalista pela Faculdade Cásper Líbero. Pós-graduada em Educação em Sexualidade pelo Centro Universitário Salesiano (UNISAL). Criadora do site Transemos. E-mail: laura@transemos.com
} 
objetiva e descritiva possível. Seus estudos evidenciaram diferenças substanciais no modo das pessoas encararem e praticarem sexo, sendo estas relações com ou sem envolvimento amoroso, compromisso ou paixão.

A sociossexualidade é uma tendência relativamente estável do indivíduo em aproximar-se ou afastar-se de práticas sexuais casuais, determinada por uma combinação de fatores herdados, aprendizado sociocultural e experiências passadas e reflete em três componentes-chave: motivação para, experiências passadas e atitudes em relação ao sexo casual (BAILEY et al., 2000; PENKE; ASENDORPF, 2008; SIMPSON; GANGESTAD, 199I; VRANGALOVA; ONG, 20I4). Ela pode ser melhor compreendida como um espectro, com duas extremidades. A variabilidade possível entre as extremidades compõe uma linha na qual os polos opostos são denominados "orientação restrita", para os indivíduos que sentem maior necessidade de proximidade para se engajar em relações sexuais e não se sentem confortáveis com práticas casuais, e "orientação irrestrita", onde estão aqueles que se identificam com o sexo sem compromisso, com pouca ou nenhuma interação emocional ou necessidade de compromisso e estão confortáveis em manter relações casuais (SIMPSON; GANGESTAD, 1991, p. 870).

Como ocorre com outros conceitos como orientação sexual e identidade de gênero, por exemplo, pode-se inferir que a maioria dos seres humanos se encontra em algum ponto deste espectro e não necessariamente em seus extremos, afinal a sexualidade é muito mais complexa, fluida e multifatorial do que imutável. Os próprios termos escolhidos - "restrito" e "irrestrito" - podem ser problematizados. A denominação de comportamentos "autônomos" e "não-autônomos" é uma opção que remete às diversas motivações possíveis existentes para um ser humano fazer sexo. Quanto mais "autônoma" e alinhada aos desejos individuais for a decisão, maiores as chances de ela não vir acompanhada de consequências indesejáveis.

\section{Comportamentos "autônomos" e "não-autônomos": achados científicos}

Um estudo publicado em 2009 no periódico Perspectives on Sexual and Reproductive Health revelou as conclusões de uma pesquisa realizada em anos anteriores com $1.3 \mathrm{II}$ jovens adultos sexualmente ativos nos Estados Unidos, cuja média de idade era 20,5 anos. Descobriu-se que os encontros sexuais mais recentes de aproximadamente $20 \%$ deles haviam sido casuais, o que o estudo classificou como "conhecidos casuais porém não parceiros não-exclusivos". Também se notou que o sexo casual era mais comum para homens $(29 \%)$ do que para mulheres (14\%). As avaliações de bem-estar psicológico, no entanto, mantiveram-se constantes e não demonstraram diferenças nem alterações significativas ao longo de toda a pesquisa, ao que a equipe concluiu no próprio estudo: "jovens adultos que se engajam em relações sexuais casuais não parecem estar em maior risco para resultados psicológicos danosos do que os jovens adultos sexualmente ativos em relações mais estáveis" (EISENBERG et al., 2009, p. 23I).

Outro estudo, por sua vez, colheu dados de estudantes heterossexuais entre 18 e 25 anos em 30 faculdades dos Estados Unidos e encontrou uma maior proporção de homens do que mulheres entre os que relataram ter tido encontros sexuais casuais no mês anterior à pesquisa ( $18,6 \%$ contra $7,4 \%)$. Os pesquisadores perceberam associações negativas entre a presença de sexo casual e o bem-estar psicológico, correlacionando-os com sofrimento psíquico, independente do gênero dos entrevistados. "Para jovens adultos, estudantes universitários, o envolvimento em sexo casual pode elevar o risco de resultados psicológicos negativos" (BERSAMIN et al., 2014, p. 43).

Um estudo publicado em 2015 no Archives of Sexual Behavior baseou-se na premissa de que existem múltiplos fatores moderadores que influenciam em como a atividade sexual casual afeta as pessoas. Os pesquisadores optaram por isolar uma variável em particular, nesse caso a diferença entre comportamentos sexuais "autônomos" e "não autônomos". Autônomos incluíam: o sujeito estava altamente atraído pela outra pessoa; o sujeito queria experimentar ou explorar sua sexualidade; o sujeito julgou que seria uma valiosa experiência de aprendizado, etc. Já os comportamentos não autônomos inclúíam: o sujeito estava bêbado; o sujeito esperava mais da interação que apenas um encontro casual; o sujeito buscava vingar-se de um ex, etc. Os resultados do estudo mostraram que, independente de gênero, pessoas que tiveram relações sexuais casuais por razões autônomas não foram, em maioria, afetadas negativamente pela atividade ou nada afetadas na verdade. Enquanto isso, pessoas que se engajaram no sexo casual por razões não autônomas tipicamente experimentaram uma queda em seu bem-estar psicológico após a atividade (DUBÉ et al., 2017).

Esse tipo de resultado demonstra que fatores como a condição psicológica prévia do indivíduo, o contexto em que a relação acontece, o tipo de interação que é estabelecida entre os envolvidos e outros diversos elementos podem influenciar diretamente nos sentimentos após uma relação casual, também influenciados e percebidos pelo contexto social.

Além disso, achados de outro estudo (VRANGALOVA; ONG, 2014) demonstraram menor influência da sociossexualidade em relacionamentos casuais curtos quando comparados a relacionamentos casuais de maior duração. $\mathrm{Na}$ amostra analisada durante nove meses, os pesquisadores concluíram que "devido à brevidade e menor ocorrência de comprometimento emocional" os 
encontros casuais de apenas uma noite tinham menor impacto no bem-estar no que dizia respeito à sociossexualidade no longo prazo.

A atividade sexual é uma prática que envolve todas as dimensões constitutivas do indivíduo. Estudos propuseram-se a investigar o quão honesto é o engajamento das pessoas ao decidirem relacionar-se sexualmente. Existem diversas motivações para alguém decidir fazer sexo e, como qualquer escolha, pode ter motivos alinhados aos valores de quem a faz ou distanciados. Ao considerar que o sexo é um ato realizado consigo mesmo ou com poucas pessoas, pode haver alguma dificuldade em compreendê-lo como um ato social. $O$ conceito de sociossexualidade é fundamental para auxiliar neste entendimento.

\section{A importância da autonomia para a atividade sexual}

Quaisquer desconfortos que sentimos em relação ao sexo são geralmente agravados pela ideia de que pertencemos a uma geração livre - e que, em consequência disso, deveríamos, a esta altura, pensar no sexo como um assunto simples e sem complicações (DE BOTTON, 20I2, p. I0).

Quando há desalinho entre desejos, comportamentos, atitudes e crenças, a possibilidade de consequências negativas como arrependimento e frustração são maiores. Entretanto, se for uma escolha consciente e com conhecimento das consequências possíveis, o sexo casual se mantém assim tão arriscado? O objetivo de fazer tais questionamentos não é ignorar os riscos atrelados à prática e possivelmente associados a ela, mas sim refletir sobre causas e consequências, perfis de seus praticantes e reais implicações da casualidade sem julgamentos moralistas ou alardes comunicativos. A autonomia envolvida na tomada de decisões seria, portanto, fundamental para tais análises.

Durante as experiências casuais, jovens podem se sentir pressionados, experimentar sensações de inadequação, arrependimento e ansiedade de performance. Verificou-se que $78 \%$ dos indivíduos superestimam o conforto alheio através de diferentes comportamentos sexuais, com homens particularmente superestimando o conforto real das mulheres com uma variedade de comportamentos sexuais nas relações casuais (GARCIA; REIBER, 20I0).

As normas sempre estão no pano de fundo, moldando nossas atitudes e expectativas (HILLS, 2015). Comprar a narrativa padrão de que homens devem ser garanhões, pegadores e ativos é, automaticamente, colocar as mulheres no exato oposto e, consequentemente, objetificá-las ao prever que elas são as "passivas" que, tal qual um objeto, têm algo que age sobre si. Entretanto, não basta considerar que a relação sexual saudável é aquela que ocorre entre dois sujeitos, capazes de desejar e sentir por si próprios: é preciso averiguar que, também eles, não estão sob o efeito de outro fenômeno - a "subjetificação".

Filósofos utilizam esse termo, 'subjetificação', para se referir ao processo pelo qual nossa autoconsciência é moldada - não independentemente, de acordo com nosso livre arbítrio, mas baseando-se nas histórias, normas e arquétipos que permeiam a cultura ao nosso redor [...]. Sujeitos sexuais se autopoliciam, observando e regulando seus próprios comportamentos a fim de criar uma identidade que esteja adequada ao ideal cultural (HILLS, 20I5, p. 160).

Isso pode significar não escolher a opção mais "autônoma" se ela significar "fugir à norma" social do grupo em que se está inserido. Assim, engajar-se em relações casuais sexuais apenas pela motivação de corresponder a um determinado ideal ou personagem, como na figura do "moderninho" ou transgressor, ainda é buscar uma validação nos pares, exterior e independente às próprias vontades e desejos. Esta motivação pode ser considerada uma atitude não-autônoma, o que, como visto nos estudos sobre impactos na saúde mental, pode ser potencialmente prejudicial ao indivíduo. O modo autônomo de se relacionar casualmente envolve autoconhecimento suficiente para reconhecer essa forma de relacionamento como alinhada aos seus valores, desejos, personalidade (podendo considerar a orientação sociossexual) e/ou momento de vida - por exemplo, um desejo temporário de dedicar-se à carreira.

A autonomia envolvida na escolha de ter ou não sexo casual demonstra a necessidade de redesenharmos socialmente o que a verdadeira liberdade sexual deveria significar e o que pode ser, de fato, uma demonstração de independência nas decisões particulares. Levar os estereótipos dos ideais masculinos ao extremo significa legitimar a reprodução, independente de sexo, de uma noção de masculinidade que pode ter consequências perigosas e violentas. Na prática, isso significa que qualquer pessoa que faça sexo casual apenas para "contar vantagem" de algum modo ou adequar-se a um ideal, desalinhado de seus valores pessoais, está comprando uma narrativa hoje associada à masculinidade que tem grandes chances de desumanizar os outros envolvidos no ato e provocar consequências negativas para seu bem-estar geral.

A sociossexualidade descontrói essa ideia ao confrontar, justamente, as interações que continuamos a construir como sociedade, que permanecem tão ou mais complexas quanto as de gerações e séculos anteriores. $O$ sexo pode tornar-se um assunto um tanto mais palatável, acessível e menos rodeado por mitos e mistérios, mas jamais será descomplicado. $O$ entendimento da própria sociossexualidade pode desempenhar um papel fundamental na compreensão dos sentimentos relacionados ao sexo, seja ele 
casual ou não. É possível visualizar os conceitos de sociossexualidade "restrita" e "irrestrita" como polos de uma linha contínua, onde nos extremos se encontra a minoria da população - a maioria, por sua vez, está em algum lugar entre estes opostos, oscilando em comportamentos e personalidades com maior ou menor propensão às orientações sociossexuais de acordo com múltiplos fatores.

Estudos aqui citados verificaram que impactos psicológicos negativos podem ser sentidos por todas as pessoas, seja na atividade sexual casual ou em outros tipos de relações sexuais, principalmente quando movidas por comportamentos "não autônomos". Sensações de desconforto podem estar ligadas à objetificação, seja por sentir-se um objeto durante a relação - observável em relatos como "fui usado", "me senti usada" etc. -, seja por tratar a parceria como um objeto sexual, ignorando seus sentimentos e necessidades.

\section{Conclusão}

Há uma necessidade geral poucas vezes atendida da frequente comprovação de nossa normalidade, que usualmente tentamos, de maneira equívoca, satisfazer através da comparação com os outros, sejam os que nos cercam e com os quais convivemos, seja com aqueles que vemos na televisão ou no cinema. Tal postura frequentemente é causa de frustração, de escolhas equivocadas e de sensação de anormalidade e inadequação em relação aos próprios desejos.

A educação em sexualidade tem no conceito da autonomia sexual um aliado de grande porte. Desenvolver esse tipo de autonomia pode ser a grande diferença entre as pessoas capazes de manter relações sexuais saudáveis e fazer escolhas alinhadas aos próprios valores das que não conseguem. Tal autonomia, no entanto, não é acabada e precisa ser exercitada. Ela é resultado de um processo multifatorial que invariavelmente passará por erros e acertos para ser desenvolvido de maneira individual.

Esse processo engloba desde a educação sexual obtida na infância até os conceitos atuais e crenças particulares sobre a sexualidade de cada ser humano. Racionalmente, é possível compreender que determinada atividade não é moralmente errada. Entretanto, ao praticá-la, aquela pessoa pode não conseguir evitar sentimentos negativos que, por sua vez, diminuem seu bem-estar como um todo. Essa complexidade e associação entre o que pensamos, como agimos e de que modo nos sentimos em relação a algo é que precisa ser analisada com a profundidade e senso crítico necessários perante situações que abrangem diversas dimensões da existência.

A autonomia sexual torna possível buscar e optar pelo sexo desprovido de culpa, frustração, julgamento, autocensura, arrependimento e dor. Em suma, conseguir identificar, de acordo com os próprios valores, qual a atividade sexual que the traz satisfação e prazer, assim como escolher relacionar-se ou não sexualmente, é o que vai colaborar para a construção de uma vida sexual verdadeiramente autônoma e consequentemente satisfatória. A sociossexualidade integra essa equação, que deve ter um alicerce sólido na educação sexual eficaz, que enxerga o ser humano como um todo, em toda a sua complexidade, e reconhece que, no que diz respeito aos comportamentos sexuais, não temos respostas únicas que servem a todos, moldes e normas a seguir nem conclusões finais, pois estamos continuamente integrados, conectados e em constante mutação. $\mathrm{O}$ caminho de entendimento e compreensão da sociossexualidade oferece a possibilidade do desenvolvimento de mais autoconfiança, seja para reivindicar o próprio prazer, aceitar seus desejos ou para posicionar-se em relação aos seus comportamentos e necessidades sexuais.

\section{Referências}

BERSAMIN, M. M. et al. Risky business: Is there an association between casual sex and mental health among emerging adults? Journal of Sex Research, v. 5I, p. 43-5I, 20I4. DOI: $10.1080=$ 00224499.2013.772088 Disponível em: https:// www.tandfonline.com/doi/abs/ I 0.1 080/00224499 .2013 .772088

BOGLE, K. A. The shift from dating to hooking up in college: What scholars have missed. Sociology Compass, n. I/2, p. 775-788, 2007.

DE BOTTON, A. Como pensar mais sobre sexo. Rio de Janeiro: Objetiva, 2012.

DUBÉ, S. et al. Consequences of Casual Sex Relationships and Experiences on Adolescents' Psychological Well-Being: A Prospective Study. Journal of Sex Research, v. 54, n. 8, p. I006-1017, 2017. DOI: http://doi.org/10.1080/00224499.2016 .I 255874 Disponível em: https://www.tandfonline. com/doi/full/10.1080/00224499.2016.1255874

EISENBERG, M. E. et al. Casual Sex and Psychological Health Among Young Adults: Is Having "Friends with Benefits" Emotionally Damaging? Perspectives on Sexual and Reproductive Health, v. 4I, n. 4, p. 23I-237, Dec. 2009. DOI: https://doi.org/I0.1363/4I23 I09. Disponível em: https://onlinelibrary.wiley.com/doi/ full/I0.|363/4I23 I09

GARCIA, J. R.; REIBER, C. Hook-up behavior: A biopsychosocial perspective. Journal of Social, 
68 Revista Brasileira de

Sexualidade Humana

DOI: https://doi.org/10.35919/rbsh.v29i2.75

Evolutional, and Cultural Psychology, v. 2, n. 4, p. 192-208, Dec. 2008.

GARCIA, J. R. et al. Sexual Hookup Culture: A Review. Review of general psychology: journal of Division I, of the American Psychological Association, v. 16, n. 2, p. I6I-I76, Jun. 2012. DOI: https://doi.org/I0.1037/a00279I I. Disponível em: https://journals.sagepub.com/doi/ abs $/$ I 0. I037/a00279 I I journalCode= rgpa

HILLS, R. The Sex Myth: the gap between our fantasies and reality. New York: Simon \& Schuster, 2015.

KINSEY, A. C.; POMEROY, W. B.; MARTIN, C. E. Sexual behavior in the human male. Philadelphia: Saunders, 1948.

KINSEY, A. C.; POMEROY, W. B.; MARTIN, C. E. Sexual behavior in the human female. Philadelphia: Saunders, 1953.

PENKE, L.; ASENDORPF, J. B. Beyond global sociosexual orientations: A more differentiated look at sociosexuality and its effects on courtship and romantic relationships. Journal of Personality and Social Psychology, n. 95, p. III 3-I I 35, 2008.

SIMPSON, J. A.; GANGESTAD, S. W. Individual differences in sociosexuality: evidence for convergent and discriminant validity. Journal of Personality and Social Psychology, v. 60, p. 870883, 1991.

VRANGALOVA, Z.; ONG, A. D. Who Benefits From Casual Sex? The Moderating Role of Sociosexuality. Social Psychological and Personality Science, v. 8, n. 5, p. 883-89I, 2014. DOI: https://doi.org/| 0.I | 77//9485506 | 4537308. Disponível em: https://journals.sagepub.com/doi/ abs/I0.1 I 77//9485506/4537308 